\title{
Osmotic demyelination syndrome in Intensive Care Unit
}

\author{
Parnandi Bhaskar Rao, Afzal Azim¹, Neha Singh², Arvind Kumar Baronia1, Anand Kumar, \\ Banani Poddar ${ }^{1}$
}

Dyselectrolytemia, especially hyponatremia is a common occurrence in hospitalized patients, and a number of dreaded complications arise out of the disorder itself and its treatment. Osmotic demyelination syndrome develops secondary to rapid correction of hyponatremia. As the disease is rare and available literature from Intensive Care Units are limited, we report our retrospective observation over 5 years. Overall incidence was $2.5 \%$ with altered sensorium and hypokalemia as most common symptom and associated factor respectively. Isolated pontine involvement was in $41 \%$ and combined pontine, and extra-pontine lesions were found in $23 \%$ of cases. All patients received supportive therapy; out of which 2 died and complete neurological recovery was seen in $24 \%$ of patients. Our findings suggest that a well organized supportive therapy and multidisciplinary approach is of more concern than many available therapeutic modalities which are still to be proved..

Keywords: Demyelination, hyponatremia, Intensive Care Unit, osmotic, syndrome

\section{Introduction}

Osmotic demyelination syndrome (ODS) is a rare clinical entity which involves both pontine and extra-pontine myelinolysis (EPM).$^{[1]}$ Although, it can occur in the presence of varied etiological factors, ${ }^{[2,3]}$ the primary pathophysiology described being either a reduced adaptive capacity of the neuroglia to large shifts in the serum osmolarity ${ }^{[4]}$ or the cellular edema caused by fluctuations in electrolyte forces results in compression and subsequent demyelination of fiber tracts. ${ }^{[5]}$ The outcome of the clinical entity is very dramatic ranging from the vegetative state to full neurological recovery. ${ }^{[2,6-8]}$ Various case reports of ODS have been published from time to time with few

\section{From:}

Department of Anesthesiology, Critical Care and Pain Medicine, All India Institute of Medical Sciences, ${ }^{2}$ Department of Anesthesiology, Critical Care and Pain Medicine, Institute of Medical Sciences and SUM Hospital, SOA University, Bhubaneswar, Odisha, 'Department of Critical Care Medicine, SGPGI, Lucknow, Uttar Pradesh, India

\section{Correspondence:}

Dr. Parnandi Bhaskar Rao, Department of Anesthesiology, Critical Care and Pain Medicine, All India Institute of Medical Sciences, Bhubaneswar - 751 019, Odisha, India. E-mail: drbhaskar.com@gmail.com

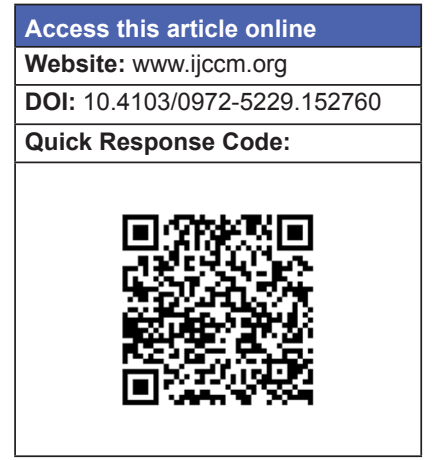

case series out of which the largest being one studied in 58 patients. ${ }^{[9]}$ Though, the exact incidence of ODS is not known, an autopsy based study documented a prevalence rate of $0.25-0.5 \%$ in the general population ${ }^{[7]}$ and $10 \%$ in patients undergoing liver transplantation. ${ }^{[7,10]}$ Being a rare disease with variable, but preventable outcome, the present study was performed with an aim to enrich the present understanding of the disease course, especially in Intensive Care Unit (ICU) patients.

\section{Subjects and Methods}

After approval from the institutional ethical committee, we retrospectively collected data and analyzed all patients admitted to our ICU with a diagnosis of ODS in the last 5 years (July' 2008 - July' 2013). Computerized database and patient records were used for data collection and analysis.

\section{Results}

Of a total of 665 patients admitted in ICU during this period, $17(2.5 \%)$ patients (11 male and 6 female) with a mean age of 32 years (12-78 years) were diagnosed as having ODS. Three patients developed ODS during their 
ICU stay, whereas the rest were transferred to the ICU from different areas of the hospital and outside. Out of the total 17 patients, seven had hyponatremia, followed by rapid correction. Two patients required imaging twice as initial computerized tomography (CT) scan for altered sensorium was essentially normal and later on magnetic resonance imaging (MRI) revealed ODS. Neurological findings, associated factors, MRI report [Figures 1 and 2] and length of ICU stay, length of mechanical ventilation and outcome is depicted [Tables 1-4].

\begin{tabular}{lc}
\hline $\begin{array}{l}\text { Table I: Neurological sign and symptoms of patients on } \\
\text { diagnosis }\end{array}$ \\
\hline & Number of patients (\%) \\
\hline Symptoms & $1 \mathrm{I}(64)$ \\
Altered sensorium & $03(17.64)$ \\
Seizures & $02(11.76)$ \\
Headache and vomiting and giddiness & $01(5.88)$ \\
Lethargy and generalized weakness & \\
Signs & \\
Pupils & $06(35.29)$ \\
Normal size and reaction & $08(47.05)$ \\
Semi dilated and sluggish reaction & $03(17.64)$ \\
Small size and sluggish reaction & \\
Muscle tone & $00(00)$ \\
Increased & $06(35.29)$ \\
Decreased & $11(64)$ \\
Normal & \\
Deep tendon reflexes & $10(58.82)$ \\
Decreased/nonelicitable & $02(11.76)$ \\
Increased & $05(29.4 I)$ \\
Normal &
\end{tabular}

Table 2: Underlying/associated clinical condition

\begin{tabular}{lc}
\hline Conditions & Number of patients (\%) \\
\hline Chronic diuretic therapy & $05(29.4 \mathrm{I})$ \\
Malnutrition & $02(1 \mathrm{I} .76)$ \\
Chronic alcoholism & $05(29.4 \mathrm{I})$ \\
Porphyria & $01(5.88)$ \\
Postsurgery & $05(29.4 \mathrm{I})$ \\
Severe hypokalemia $(\leq \mathrm{I} .5 \mathrm{mEq} / \mathrm{L})$ & $07(4 \mathrm{I} .17)$ \\
Hypophosphatemia $(<3 \mathrm{mmol} / \mathrm{L})$ & $02(1 \mathrm{I}) .76)$ \\
\hline
\end{tabular}

Where $n=17$

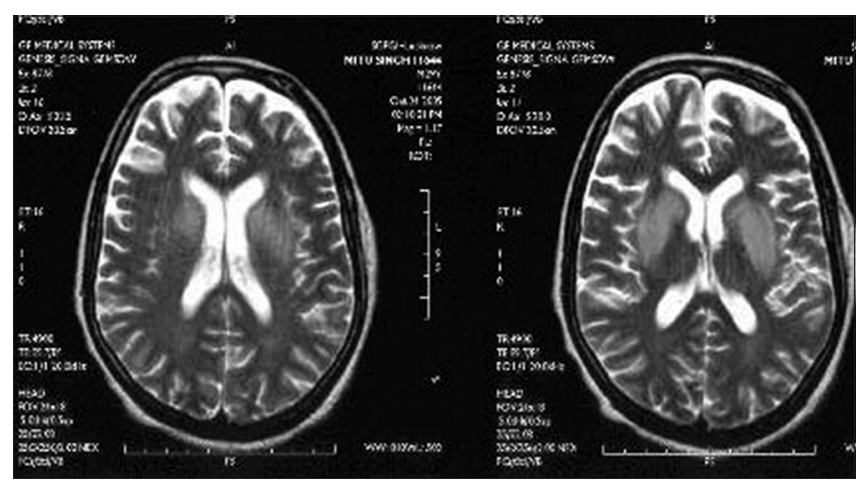

Figure I: T2-weighted magnetic resonance imaging showing areas of demyelination in bilateral basal ganglia and thalami, known as extra-pontine myelinolysis

\section{Discussion}

In the present analysis, we found an ODS incidence of $2.5 \%$ over 5 years. Altered sensorium was found to be the most common symptom and hypokalemia as the most common underlying associated factor. MRI findings revealed isolated pontine involvement in $41 \%$, both pontine and extra-pontine involvement in $23 \%$ of the cases. All the patients received supportive therapy; of these 17 patients complete neurological recovery occurred in $24 \%$ of the patients.

True incidence of ODS is unknown until date. In a study of 3000 brains examined postmortem, there were 15 cases of asymptomatic central pontine myelinolysis (CPM). ${ }^{[11]}$ We evidenced an incidence of $2.5 \%$ in our ICU with a reported $12 \%$ mortality.

\section{Associated factors}

Literature evidence speaks in favor of many associated factors like syndrome of inappropriate antidiuretic hormone, burns, chronic alcoholism, malnutrition, psychogenic polydipsia, liver transplantation, dialysis, hyperemesis gravidarum etc., which predispose one to develop ODS. ${ }^{[12]}$

The most common associated factor seen in this study was severe hypokalemia defined as serum potassium level $\leq 1.5 \mathrm{mEq} / \mathrm{L}$ ( $41 \%$ ), followed closely by chronic alcoholism, prolonged diuretic therapy and postoperative fluid therapy each approximately seen in $30 \%$ of the cases. In a similar review, Lampl and Yazdi found alcoholism in $40 \%$ and liver transplantation in $17 \%$ of the cases of ODS. ${ }^{[10]}$ Almost all patients with chronic diuretic therapy had dyselectrolytemia, whereas more than half (4 out of 7)

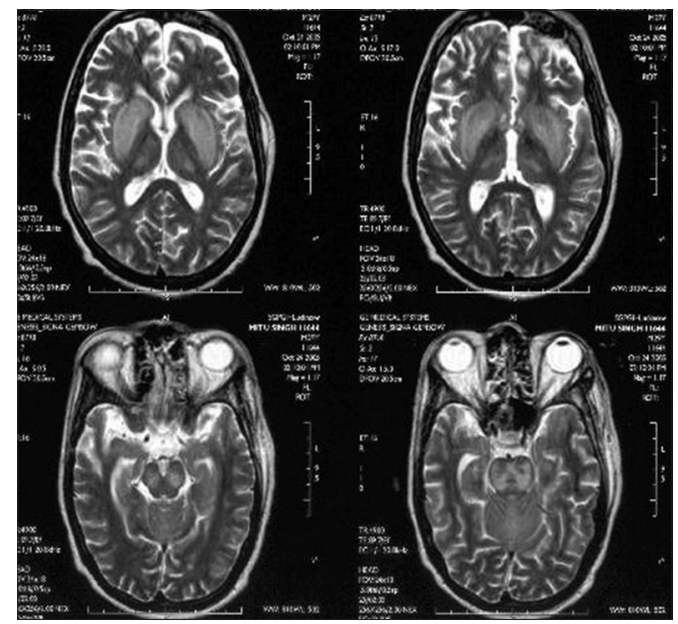

Figure 2: T2-weighted magnetic resonance imaging showing symmetrical hyperintensity of midbrain and pons suggestive of both pontine and extra pontine myelinolysis 


\begin{tabular}{lc}
\hline Table 3: MRI findings & \\
\hline Findings & Number of patients (\%) \\
\hline Central pontine myelinolysis & $7(41.18)$ \\
Extrapontine myelinolysis & $6(35.29)$ \\
Both pontine and extrapontine myelinolysis & $4(23.53)$ \\
\hline
\end{tabular}

Where $n=17$. MRI: Magnetic resonance imaging

\begin{tabular}{|c|c|c|}
\hline Variable & Sub-variable & $\begin{array}{l}\text { Number of } \\
\text { patients (\%) }\end{array}$ \\
\hline \multirow[t]{4}{*}{ Outcome } & Complete neurological recovery & $4(23.52)$ \\
\hline & Conscious with some neurological deficit & $8(47.05)$ \\
\hline & Vegetative state & $3(17.64)$ \\
\hline & Expired & $2(11.76)$ \\
\hline \multicolumn{2}{|c|}{ Length of ICU stay in days (mean \pm SD) } & $30.94 \pm 13.7$ \\
\hline \multicolumn{2}{|c|}{ Length of $M V$ in days (mean $\pm S D$ ) } & $24.94 \pm 11.03$ \\
\hline
\end{tabular}

of those having severe hypokalemia had a history of diuretic therapy.

The general background which might add to the ease of development of ODS in these sub-group of patients is a disordered state of solute metabolism or a general deficiency of organic osmolytes. This in itself predisposes cells to undergo a change in size and volume, thus makes prone for cell shrinkage. ${ }^{[11,12]}$

\section{Clinical presentation}

The classical picture is a patient who presented with seizures and altered sensorium due to hyponatremia, had a rapid recovery with normalization of serum sodium, but only to deteriorate again. This second phase correlates with a rapid correction of serum sodium levels and development of ODS. ${ }^{[2]}$

The clinical picture is usually very wide depending upon the area in the central nervous system involved with demyelination. When pons along with corticobulbar and corticospinal tracts are involved, the classical presentation is dysarthria and dysphagia along with flaccid paralysis changing over to spastic later on. EPM is characterized by tremor, ataxia and movement disorders like mutism, Parkinsonism, dystonia, and catatonia. ${ }^{[11]}$ If the lesion extends further, then it may result in pupillary, oculomotor dysfunction, and locked-in syndrome. When there is a combination of pontine and extra-pontine lesions, the clinical picture is usually mixed and variable. ${ }^{[2]}$

It has been documented that ODS has a peak incidence in adults with a male preponderance, possibly due to the association of risk factors like alcoholism in the particular age group. ${ }^{[10]}$ We observed a similar male preponderance $(64 \%)$ and none of the patients in this study belong to pediatric age range.

In this case series, out of 17 patients, 11 (64\%) had altered sensorium as the most common clinical presentation while only $3(17 \%)$ had episodes of seizures. Flaccid quadriparesis was seen in 6 patients $(35 \%)$ and surprisingly, $64 \%$ of the patients had normal muscular tone.

\section{Radiology and osmotic demyelination syndrome}

Radiology plays a major role in the diagnosis of ODS. Not only it provides support to the clinical suspicion, it helps in excluding other possibilities also.

Demyelination appears on CT as an area of decreased attenuation but unfortunately it may underestimate the true extent of the disease process. With greater sensitivity, MRI is the modality of choice, which speaks about the number and extent of lesions in both pontine and extra-pontine areas.

Acute demyelinating lesions are visible as symmetric and hypointense lesions on T1-weighted and hyperintense in T2-weighted images in the subacute phase. The usual picture appears as a tridents shaped area of hyperintense or hypointense lesion in the central pons with sparing of the ventrolateral pons and do not enhance with contrast. ${ }^{[12]}$ Lesions on MRI may appear days to weeks after the onset of symptoms and these may or may not resolve even though there is partial or complete clinical recovery. ${ }^{[6,8]}$

Extra-pontine involvement occurs with or without CPM. In the present study, MRI revealed involvement of the central pons in 7 patients (41\%), extra-pontine lesions in $6(35 \%)$ and combined involvement in $4(24 \%)$ patients. Similarly, Gocht and Colmant in their series of 58 cases, reported isolated CPM in about $50 \%$ of the cases, combined lesions in $30 \%$ of the cases and isolated EPM in about $20 \%$ of the cases. ${ }^{[9]}$

\section{Treatment and outcome}

Once diagnosis is established, treatment is supportive. Reports on random case reports and small case series have found benefits of a multiply of treatment modalities such as steroids, intravenous immunoglobulin, and thyrotrophin releasing hormone, re-induction hyponatremia, administration of organic osmolytes (urea, Myoinositol), and dopaminergic compounds, especially in EPM cases etc. ${ }^{[2,8]}$ As there is no randomized human trial till date, all these possible therapies are not yet recommended in ODS patients. 
Abbott et al. in a study of 34 ODS patients reported a mortality of $6 \%$ whereas $30 \%$ completely recovered, $32 \%$ had some debilitating illness, but independent, and a similar number of patients were recovered but dependent. ${ }^{[11]}$ Martin reported in their review an overall mortality of $40-50 \%$ in ODS and a lower rate in those subgroup of patients admitted in intensive therapy unit $(10-20 \%){ }^{[2]}$

In the present study of 17 patients, we observed complete neurological recovery in $24 \%$ of patients, recovery with some deficit in $47 \%$, vegetative state in $18 \%$ of patients. The mortality in this study was $12 \%$ which corroborates with the findings of Martin in their subgroup of ICU patients. ${ }^{[2]}$

Literature evidence varies widely with regards to mortality ranging from $6 \%$ to $90 \% .{ }^{[6,9]}$ Whereas Menger and Jörg reported $40 \%$ of patients recovered without any noticeable neurologic sequelae. ${ }^{[6]}$ One study had reported $25 \%$ of patients developed grave neurological outcome requiring lifelong support. ${ }^{[12]}$

This study results reflect the true area of concern is not one of the available but unproven multiple modalities of therapy rather it requires a well-organized supportive therapy and multidisciplinary approach to have a better outcome. ${ }^{[6]}$ In addition, the focus has to be preventive not therapeutic as ODS is not a disease in itself rather a complication.

\section{References}

1. Adams RD, Victor M, Mancall EL. Central pontine myelinolysis: A hitherto undescribed disease occurring in alcoholic and malnourished patients. AMA Arch Neurol Psychiatry 1959;81:154-72.

2. Martin RJ. Central pontine and extrapontine myelinolysis: The osmotic demyelination syndromes. J Neurol Neurosurg Psychiatry 2004;75 Suppl 3:iii22-8.

3. Ashrafian H, Davey P. A review of the causes of central pontine myelinosis: Yet another apoptotic illness? Eur J Neurol 2001;8:103-9.

4. Verbalis JG, Gullans SR. Rapid correction of hyponatremia produces differential effects on brain osmolyte and electrolyte reaccumulation in rats. Brain Res 1993;606:19-27.

5. Singh N, Yu VL, Gayowski T. Central nervous system lesions in adult liver transplant recipients: Clinical review with implications for management. Medicine (Baltimore) 1994;73:110-8.

6. Menger H, Jörg J. Outcome of central pontine and extrapontine myelinolysis $(\mathrm{n}=44)$. J Neurol 1999;246:700-5.

7. Kleinschmidt-Demasters BK, Rojiani AM, Filley CM. Central and extrapontine myelinolysis: Then.and now. J Neuropathol Exp Neurol 2006;65:1-11.

8. Brown WD. Osmotic demyelination disorders: Central pontine and extrapontine myelinolysis. Curr Opin Neurol 2000;13:691-7.

9. Gocht A, Colmant HJ. Central pontine and extrapontine myelinolysis: A report of 58 cases. Clin Neuropathol 1987;6:262-70.

10. Lampl C, Yazdi K. Central pontine myelinolysis. Eur Neurol 2002;47:3-10.

11. Abbott R, Silber E, Felber J, Ekpo E. Osmotic demyelination syndrome. BMJ 2005;331:829-30.

12. King JD, Rosner MH. Osmotic demyelination syndrome. Am J Med Sci 2010;339:561-7.

How to cite this article: Rao PB, Azim A, Singh N, Baronia AK, Kumar A, Poddar B. Osmotic demyelination syndrome in Intensive Care Unit. Indian J Crit Care Med 2015; $19: 166-9$

Source of Support: Nil, Conflict of Interest: None declared.

\section{New features on the journal's website}

\section{Optimized content for mobile and hand-held devices}

HTML pages have been optimized of mobile and other hand-held devices (such as iPad, Kindle, iPod) for faster browsing speed. Click on [Mobile Full text] from Table of Contents page.

This is simple HTML version for faster download on mobiles (if viewed on desktop, it will be automatically redirected to full HTML version)

\section{E-Pub for hand-held devices}

EPUB is an open e-book standard recommended by The International Digital Publishing Forum which is designed for reflowable content i.e. the text display can be optimized for a particular display device.

Click on [EPub] from Table of Contents page.

There are various e-Pub readers such as for Windows: Digital Editions, OS X: Calibre/Bookworm, iPhone/iPod Touch/iPad: Stanza, and Linux: Calibre/Bookworm.

\section{E-Book for desktop}

One can also see the entire issue as printed here in a 'flip book' version on desktops.

Links are available from Current Issue as well as Archives pages.

Click on View as eBook 